\title{
Del "giro aplicado" de la ética al "giro cívico" de la bioética
}

\section{Lizbeth Sagols}

\author{
Teresa López de la Vieja, Bioética \\ y ciudadanía. Nuevas fronteras de la ética. \\ Madrid, Biblioteca Nueva, 2008, 312 pp.
}

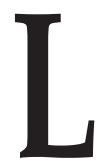

a bioética se ha visto capitalizada en gran medida por el discurso liberal: el predominio de la autonomía, la libertad, la imparcialidad del Estado y la asunción del cambio de los tiempos. Tal es el modelo americano de pensamiento que ha logrado imponerse en diversos países, sobre todo en aquellos - como el nuestro- que tiende a imitar a fin de sentirse dentro de lo que marca la novedad y el supuesto "avance". Bioética y ciudadanía. Nuevas fronteras de la ética, de Teresa López de la Vieja, es una disertación filosófica que, con base en una amplia bibliografía de filósofos europeos e incluso americanos críticos del liberalismo, nos ofrece un punto de vista distinto atendiendo sobre todo al análisis crítico de las transformaciones que ha sufrido la bioética y sus peculiares necesidades contemporáneas. El libro está dividido en tres grandes partes, cada una de las cuales comprende diversos capítulos: I. Bioética liberal y derechos humanos, II. Temas de bioética y III. Bioética cívica. Los capítulos son catorce, de suerte que sería excesivo nombrarlos todos, pero merece la pena hacer alusión a los que tratan los temas más originales como "Bioética. Contexto e ideología", "Crisis de la bioética liberal", "Bioética y feminismo", "Medio ambiente y sociedad y "Ética para la ciudadanía". Además, otros capítulos tratan temas de sumo interés como "Ética de la investigación científica", "Eugenesia y terapia", "El final de la vida. Argumentos imperfectos".

La perspectiva general del libro es bioético-política. Se trata, como el título lo indica, de demostrar la liga íntima entre la bioética actual (no la de hace treinta años) y la creciente necesidad de participación ciudadana e inclusión de la perspectiva comunitaria en las discusiones y en las regulaciones. Además están presentes en el texto, desde luego, la perspectiva legal, la histórica y, en gran medida, la crónica de casos concretos. En cuanto a lo legal, se toma siempre como marco general de la reflexión, algunas de las siguientes norma- 
tividades: la Carta de los Derechos Fundamentales de la Unión Europea, la Declaración Universal de Bioética y Derechos Humanos de la UNESCO de 2005 , el Convenio de Oviedo, y en algunos temas como el de la eugenesia, la Ley de Investigación Biomédica de España de 2007. La historia está presente en los antecedentes del surgimiento de la bioética en los setentas, particularmente en la exposición de la ideología liberal de la "nueva frontera" expresada por John F. Kennedy, pero también en la exposición del devenir de la bioética que va de la preocupación por la ciudadanía manifestada por Van Rensselaer Potter al modelo liberal y pragmático imperante en los setentas y ochentas, y también en los antecedentes nazis de la investigación clínica y biomédica que constituye un antecedente imprescindible de la postura de Europa mucho más cauta que la estadounidense. La crónica de casos concretos se presenta casi siempre al inicio de los temas y sirve de punta de lanza al desarrollo de la exposición. Por ejemplo, en el capítulo sobre "Bioética y feminismo" se apela a los tres casos de mujeres que abrieron e intensificaron la discusión sobre eutanasia: el de Karen Quinlan, Nancy Cruzan y Terry Schiavo; el capítulo sobre medio ambiente se ilustra con las catástrofes ocasionadas en Algeciras y en Galicia, respectivamente, por los buques New Flame en 2007 y Prestigie, en 2002. El horizonte de la disertación filosófico-política sobre la bioética es amplio y completo.

La preocupación central del texto es -según hemos dicho ya- mostrar la creciente necesidad de incluir la participación ciudadana y, por ende, la perspectiva comunitaria, en decisiones sobre los temas de bioética. Para sustentar esto, Teresa López de la Vieja recorre de forma crítica las etapas por las que ha atravesado la bioética. Nos demuestra que desde los orígenes de esta disciplina, Potter defendía que los especialistas compartieran sus reflexiones con los pacientes e incluso con la sociedad en general (p. 25). Pero por diversas causas, la perspectiva de Potter, lamentablemente, no proliferó y la discusión bioética quedó confinada a círculos de especialistas que buscaban el consenso entre ellos mismos y quienes además, adoptaron un modelo liberal, pragmático de defensa de los derechos.

La autora nos hace ver con gran perspicacia analítica y suficiente documentación que el liberalismo fue promovido por la ideología de lo que J. F. Kennedy denominó "nueva frontera": la generación defensora de las libertades y los derechos aun cuando ello implicara caer en la contracultura (p. 23). Gracias a ello se conquistó, entre otros hechos, la abolición del racismo, pero a la vez se impulsó el liberalismo a ultranza que colocó la autonomía del individuo así como la neutralidad e imparcialidad del Estado como criterios supremos sin considerar otros valores. Tal liberalismo marcó de forma decisiva los primeros quince o veinte años de la bioética. A la vez, esta disciplina, en tanto ética aplicada, se vio influida por el pragmatismo, pues lo más importante en el 
"giro aplicado" de la ética era resolver los casos concretos de la práctica clínica y en ellos imperaba el criterio de la utilidad mucho más que la elaboración de una teoría que sirviera para un mayor número de casos y que precisara conceptos clave. El pragmatismo conllevó serias carencias teóricas, filosóficas en especial (p. 75). Pero lo grave de esta situación es que bajo los supuestos del liberalismo y el pragmatismo, así como bajo la voluntad de consenso entre los expertos, se cometieron abusos imperdonables en la investigación médica y científica como por ejemplo, el tan citado proyecto de Tuskegge y el proyecto Human Radiation Interagency Working Group. No podía continuarse bajo este marco de referencia.

Por otra parte, en opinión de Teresa López de la Vieja, el avance mismo de las ciencias de la vida y las biotecnologías ha impuesto también un cambio. Si bien en un inicio la bioética se dedicó a reflexionar sobre los problemas de la práctica clínica, a partir de los años noventas se enfrenta a las tecnologías genéticas aplicadas al ser humano, tecnologías como la investigación en stem cells, la clonación terapéutica, la terapia génica, se extienden de manera global e imponen a la bioética la necesidad de proponer cierta regulación para todos los países. El problema es que desde el marco de la autonomía y los casos particulares no se puede atender a los retos actuales.

En primer lugar, las nuevas tecnologías genéticas no sólo implican la autonomía de las personas, implican la dignidad e integridad de quienes se someten a ellas y de segundos afectados. Es cierto - reconoce la autora- que la autonomía es imprescindible en bioética, pero es insuficiente. No se puede pensar tan sólo en la libertad de las personas y en la defensa de los derechos individuales. Hay mucho más que esto. Se requiere proteger la dignidad y la integridad, y no sólo defender sino incluso promover los derechos de los excluidos o los diferentes. Se hace necesario incluir al ciudadano real, efectuar un "giro cívico" - precisa la autora- en la bioética. Asimismo, se requiere pensar en la comunidad local y, a la vez, en la global, apoyándonos en un modelo político "republicano" que amplíe el horizonte del liberalismo. El modelo republicano es capaz de incluir la autonomía sin absolutizarla, ya que pone atención al "terreno de lo común" y es capaz de defender la neutralidad del Estado sin caer en la indiferencia de éste ante la promoción y protección de los derechos frente a la salud y el bienestar.

Por lo anterior, uno de los temas tratados con mayor profundidad en el libro es justamente el esclarecimiento teórico de los conceptos de imparcialidad y neutralidad del Estado. La autora manifiesta gran interés en dejar claro que ninguno de estos conceptos puede implicar indiferencia del Estado ante los casos de conflicto permitiendo que cada quien haga lo que quiera. Ambos conceptos implican la no intromisión del Estado en los proyectos y concepciones de vida particulares, lo cual es bien venido, pero nos pueden conducir, como 
ha ocurrido en el modelo liberal, a una falta de responsabilidad ante las malas prácticas en la atención a la salud y la afectación que pueden tener las decisiones particulares en la comunidad. El republicanismo es el modelo político capaz de asumir esta responsabilidad, y en esta medida, introduce valores más amplios que la mera autonomía: pone énfasis en la justicia global, la tolerancia, y la solidaridad (pp. 78-83). El republicanismo enriquece el ámbito de valores de la bioética.

En opinión de Teresa López de la Vieja, dicho modelo está presente en la Carta de los derechos fundamentales de la Unión Europea y en la Declaración universal sobre bioética y derechos humanos, textos que destacan precisamente la dignidad, la integridad y (cabe añadir) la vulnerabilidad de los excluidos. En particular, la mencionada Carta hace énfasis en el consentimiento informado, en el rechazo a la selección de embriones, así como a las prácticas eugenésicas perfectivas y la clonación reproductiva, por considerar que se trata de prácticas que atentan contra la dignidad e integridad de las personas (pp. 41-42). Y ello no significa en modo alguno que Europa no sea para nada liberal, este enfoque es común a Estados Unidos y al "viejo mundo", pero este último pone especial atención en lo normativo, en la defensa de la comunidad, debido a un pasado histórico marcado por el racismo y la violencia (pp. 42-50).

En cuanto al consenso, el cambio de la bioética actual está en que si bien éste es una idea reguladora, no puede ser ya el acuerdo entre los especialistas que participan en los comités de bioética o de ética de la investigación. Por principio de cuentas, dichos comités han de transformarse incluyendo no sólo la interdisciplina, sino las voces de los ciudadanos excluidos y diferentes. No vale que los especialistas continúen operando sobre una "pax bioética" bajo la cual se apoyaron proyectos ad hoc para supuestas necesidades científicas como el proyecto de Tuskegge y el de Human Radiation Interagency Working Group. Para hacer ver que el consenso no ha de ser prioritario, la autora señala con gran acierto que en relación con las tecnologías genéticas reproductivas se hace indispensable escuchar la "otra voz" de las mujeres y enfrentarnos al conflicto, a la diferencia que representan los grupos tradicionalmente excluidos. En segundo lugar, hemos de estar conscientes de que en estos temas, el acuerdo entre países e individuos es sumamente difícil. Las regulaciones internacionales han de dar cabida a la independencia de los países para regirse por sí mismos dentro de un marco común.

A partir de tal panorama general, Teresa López de la Vieja trata distintos temas entre los que destacan a mi modo de ver, los de "Ética de la investigación científica", "Bioética y feminismo" y "Medio ambiente y sociedad". El primero de éstos culmina con una reflexión sobre el papel destacado que han de tener los comités éticos de investigación como modelos de inclusión de las diferentes 
voces ciudadanas y de un buen gobierno o gobernanza. Tales comités han de ir más allá de la mera supervisión y control de los proyectos y han de desplegar su potencial constructivo en la supervisión de la calidad y en la buena práctica. La calidad ha de responder a criterios técnicos, mientras que la buena práctica ha de implicar el buen gobierno en la revisión de los proyectos. Ello requiere de criterios muy precisos que hoy en la Unión Europea se conocen con el nombre de gobernanza: autorregulación, apertura, inclusión del diferente, efectividad, coherencia, rendición de cuentas. Los comités de ética en investigación han de operar conforme al republicanismo y han de hacer aportaciones importantes a la participación social y las buenas prácticas. Sin un buen gobierno, afirma la autora, no puede haber buenas prácticas; éstas no dependen sólo de la calidad sino que implican el horizonte político.

Al tratar el tema de "Bioética y feminismo" el libro muestra una de sus virtudes peculiares: pone de manifiesto que la bioética ha tenido un carácter androcéntrico: López de la Vieja afirma, con razón, que durante treinta años las mujeres han sido invisibles en la práctica clínica, en la investigación, en las políticas sanitarias. De esta forma, hace evidente que el despliegue espectacular de la bioética ha sido insuficiente, pues no se ha deshecho de los prejuicios más comunes sobre las diferencias de género. El bienestar de la mitad de la población no ha sido un tema relevante para esta disciplina (p. 177). Fue el propio feminismo el que a partir de los ochentas hizo ver las necesidades reales de las mujeres, no sólo critica la falta de una mirada femenina, sino que impone el respeto a las diferencias en el análisis de los problemas y la necesidad de ampliar las miras del discurso bioético. Gracias a él existe conciencia de la especial vulnerabilidad de las mujeres en el ámbito clínico, en los ensayos de investigación, en la distribución de recursos, medicamentos y tratamientos. Y, sin embargo, la intención del feminismo no es tan sólo reivindicar a las mujeres, sino hacer ver otros puntos de vista, por ejemplo, que todos somos vulnerables ante la enfermedad y que es posible elaborar una visión alternativa sobre la atención médica y la calidad de vida. La categoría clave en el feminismo, como el de Caroll Gilligan, es el cuidado, el cual encierra la responsabilidad ante las necesidades de los otros. El cuidado no es asumir a la mujer como cuidadora, sino a cualquier ser humano como capaz de responsabilizarse de sí mismo y de su propio contexto. El cuidado nos hace pasar de la abstracción de la enfermedad al contexto específico del enfermo, introduce, al decir de Gilligan y López de la Vieja, un equilibrio entre juicio imparcial e información contextual o entre principios universales y valoración de los casos reales. En esta medida ayuda a reconstruir la teoría de la justicia, a trabajar por la equidad, pues aunque no es lo mismo que el principio de justicia, conduce a solucionar las necesidades de los agentes (p. 183). Y al hacer valer la diferencia de la mujer y de todos los diferentes, el feminismo demuestra precisamente, afirma la 
autora, que es indispensable realizar el "giro cívico" en la bioética. De ahí, la importancia de este capítulo.

Al ocuparse de "Medio ambiente y sociedad" la autora centra su aportación en mostrar la necesidad de trascender, por un lado, el catastrofismo y, por el otro, el biocentrismo en que se ha concentrado la ética ambiental. Es un hecho que los problemas ambientales traen catástrofes humanitarias y para otras especies. Más aún, las catástrofes son una razón poderosa para reflexionar sobre los excesos de la intervención humana y su impacto sobre otras especies. Pero no está claro que los argumentos negativos y la insistencia en los efectos indeseables de nuestros excesos logren imponer un cambio de conducta en los ciudadanos, pues la mayoría de éstos no sienten las graves consecuencias del mismo modo que los más desprotegidos. Por ello, nos hace ver T. López de la Vieja, conviene explorar las ventajas de los argumentos positivos, a favor del equilibrio y la sostenibilidad de recursos (p. 192). Hay que insistir en que las obligaciones que tenemos con las otras especies y el planeta en general son tan firmes como las que tenemos con nuestros iguales, por ello no debemos caer en excesos.

Frente al biocentrismo, que pareciera la postura más coherente para defender el planeta, la autora nos hace ver la dificultad de aceptarlo debido a que implica un igualitarismo: todo ser vivo, por el mero hecho de serlo tiene igual valor y merece igual consideración moral que cualquier otro ser. Se borran así las diferencias entre agentes y pacientes morales, en especial, se olvida que lo peculiar del ser humano es, justo, la capacidad moral y política de responsabilizarse del ambiente.

El punto de partida en ética ambiental es para López de la Vieja asumirnos como responsables de la biosfera y ello se puede hacer desde un "antropocentrismo moderado", aquel que asume la diferencia del ser humano sin concederle privilegios en el abuso de los recursos. ${ }^{1}$ Desde tal antropocentrismo se trata de regular políticamente nuestras acciones hacia el medio ambiente, incluso de establecer nuevos derechos, como el derecho a un ambiente sano, que nos lleven a proteger el medio y a otras especies. Sin la política, sin la formulación de leyes no se avanzará en este tema. Nuestra especie tiene un doble compromiso, primero proteger a las generaciones presentes y futuras, y por ello también, de forma derivada proteger el medio ambiente para que todos disfruten de él en las mejores condiciones. Hay una justicia intergeneracional, que como advierte V. van DeVeer, nos conduce a una justicia entre

${ }^{1}$ Con esto la autora recuerda el antropocentrismo débil de Bryan Norton y de Antony Weston. Vid. B. Norton, "Enviromental ethics and weak anthropocentrism", en Holmes Rolston III, coord., Environmental ethics. Blackwell, 2002, pp. 163-174 y A. Weston, "Beyond intrinsic value. Pragmatism in Environmental Ethics", en ibid., pp. 307-318. 
especies. Finalmente, la democracia es el marco apropiado para deliberar sobre las políticas responsables del medio ambiente, pues permite la participación activa de los ciudadanos y ha de exigir de éstos una auténtica deliberación política más que una mera protesta de indignación, como suelen hacer ciertos grupos que saben negociar políticamente. Para que exista una democracia verde se requiere la participación deliberativa e informada de los ciudadanos (pp. 198-206).

Ética y ciudadanía es, en definitiva, un libro que discurre por caminos novedosos, nada trillados en bioética y que aporta una mirada fresca, no enclaustrada en el liberalismo bioético o en la casuística, menos ciega a la transformación de la bioética y nada complacida con la autonomía a ultranza que todo lo permite en función de la libertad y el "cambio de los tiempos". En Bioética y ciudadanía comprendemos que hay poco afán de cambio en seguir una bioética simplemente "liberal" y pragmática, y hay mucho de innovación en responsabilizarnos de la vida en común. 